\title{
Challenges and Opportunities for Grassroots Organizations-Led Peacebuilding and Cohesion in Kibra Informal Settlement, Kenya
}

\author{
Christine JumaAgaya*, Godfrey Ungaya, Emily Okuto \\ Kisii University, Kenya
}

*Corresponding Author: Christine JumaAgaya, Kisii University, Kenya

\begin{abstract}
Evidence suggests that grassroots organizations have been at the forefront of attempting to establish stability and harmony in Kibra informal settlement. However, the grassroots-led interventions have not been successful in eliminating recurrent violence and tensions in the informal settlement. This study therefore sought to examine the challenges undermining the effort of grassroots organizations towards community peace and cohesion in Kibra informal settlements, Kenya.The study was grounded on the intergroup contact, functionalism and conflict transformation theories to explain the relationship between grassroots organizations and the development of peace and cohesion in Kibra informal settlement. Using a descriptive research design, the study purposively sampled three areas in the informal settlement namely Sarang'ombe, LainiSaba and Kibra because they are the locations that make up the informal settlement. 13 grassroots organizations active in peace and community cohesion activities in the informal settlement were sampled for the study. A sample size of 384 was obtained from the target population comprising of heads of households, government agencies and grassroots organizations. Data was collected using interviews, Focus Group Discussions and questionnaires. The study established that the grassroots organizations working in peace and community cohesion in Kibra informal settlement lacked proper government support, an enabling framework for mainstreaming their operations and sustainable funding streams to support the organizations' programs and activities. The study recommends the development of a policy framework that mainstreams the work of the grassroots organizations. Other opportunities would include consultative dialogues that seek to identify sustainable programs that address the root causes of the recurrent conflicts.
\end{abstract}

Key words: Opportunities, challenges, grassroots organisations, community peace and cohesion

\section{INTRODUCTION}

This study conceptualizes grassroots organizations as basic autonomous non-profit support networks formed, owned and led by local people in the urban informal settlements.The organizations' members design the approach towards achieving their aims and objectives while being open to collaborate with other organizationsthat may supplement their resources needed to execute their projects and programs. According to Satterthwaite et al (2011) there has been a growing network of grassroots organizations in the urban informal settlements that have made major progresses in improving the wellbeing of the dwellers in such settlements. Despite these good intentions, grassroots organizations are faced with a myriad of challenges that oftentimes militate against the attainment of their objectives, especially in cultivating community peace and cohesion.

\section{RESEARCH QUESTION}

This study sought to establish the challenges undermining the efforts of grassroots organizations in promoting community peace and cohesion and the opportunities that exist which if utilized can alleviate the situation.

\section{THEORETICAL FRAMEWORK}

This study was grounded on Allport's (1954) intergroup contact theory, developed from the works of Lett (1945) and William (1947), who proposed that contact between members of different groups could help reduce prejudice and improve social relations. This theory presents four conditions under which contact between erstwhile warring groups yields a reduction in prejudice. These are equal status among groups within the situation, active attainment of common objectives by the group, cooperation among group members and an explicit and unambiguous support for intergroup contact by institutional authority, law or customs. Building on the conditions, Stephan and Stephan (1992), argue that prejudice and conflict are intractable characteristics of the contemporary society and 
peaceful coexistence between groups do not come naturally but rather requires assistance in terms of programs that encourage contact to help reduce conflict and prejudices. This theory therefore asserts that there is need for groups to experience contact with one another to establish mutual appreciation and ease intergroup tension.Pettigrew and Tropp (2008)contributing on the significance of contact in reducing prejudice observed that knowledge about other groups enables members to see the similarity in diversity, reduces anxiety about group contact and increases empathy, which in turn improves intergroup attitude.Contextually, grassroots organizations have emerged in the urban areas especially in the informal settlements as support network groups to tackling and alleviating some urban problems which jeopardize cohesion and to a certain degree the safety and security brought about by diversity. The grassroots organizations help to broaden the network of collaboration and enable members to work together to pursue shared goals.

\section{LITERATURE REVIEW}

The peace and cohesion functions that grassroots organizations perform are essentially meant to be led by governments. However, at times, the government which is supposed to cultivate and nurture these ideals has tended to be an actor in the processes that generate the conflicts that undermined peace and cohesion in the first place. The involvement of government agencies in violence undermines the trust communities have in it as well as its authority in creating the mechanisms necessary for peace and cohesion to flourish. Cox, Orsborn, and Sisk (2014) argue that it is the mistrust in government institutions as well as inter-personal mistrust that has provided the environment necessary for grassroots organizations to sprout and thrive.

The Cantle report (2018) claims that in order to overcome the separations ushered in by community conflict and unrest based on racism and negative ethnicity, great emphasis should be on community because it help to develop shared values across race and ethnic groups and to overcome the separations ushered in by community conflict and unrest. The same report also underscores a greater community involvement in the development of cohesion especially in disadvantaged urban settlement in order to create stronger sense of community and ownership of the peace and cohesion. Schiefer and van der Noll (2017) argue that cohesion is a vital social quality of societies, because it leads to the development of togetherness and team spirit that involves individuals, groups and societal institutions. It allows for development of good social relationship among people, helps them to feel connected to the society and to develop positive orientation towards a common good.

Despite the acknowledgement of the effort made by grassroots organizations in the establishment of community peace and cohesion,these organizations face diverse challenges some of which are common across grassroots organizations while some are unique to specific organizations.

According to Satterthwaite et al, (2011) grassroots organizations in informal settlements experience e slow process of partnership and support from the government that take a long time to come due to government bureaucracies or if it comes it proves to be less than what was promised or sometime the support to the grassroots organizations face unexpected blockages. A research carried out by Tanvi et al (2019) in Bengaluru informal settlement in India revealed that it is the government's apathy and disregard of the activities of grassroots organizations together with their restriction control, regulations that hinder the achievement of community peace and cohesion in the informal settlement. The grassroots organizations in the informal settlement need to draw the support for community peace and cohesion initiatives from other sources such as NGOs and civil societies that can not only improve peace and cohesion through certain interventions but can also act as intermediaries between grassroots organizations in informal settlements and the governing agencies.

Another prevalent challenge to grassroots organizations initiative to peace and community cohesion in the informal settlement is limited access to financial resources. A study by Cawood (2019) across Dhaka revealed that grassroots organizations in the informal settlementsdepend on the membership contribution of the locals who generally have low income, which may not be enough to sustain the organizations. Building a cohesive community require sustainability and long term initiatives and funding yet many funders favour short term programs. Lack of funds hinder the effectiveness of these grassroots organizations to travel and reach out to communities to enhance peace and cohesion, hold public forums where actors can meet and share ideas and galvanize the support of young people. Most of the grassroots organizations have no office space, a further constraint to organizational capacity to 
bring the communities together. According to Barker et al. (2004), grassroots organization in informal settlements rely on donor funding which creates a significant risk to the identity, autonomy and mission of grassroots organizations. Howell and Pearce (2002) also assert that donor priorities regulate and restrict the activities of grassroots organizations to make sure that they are aligned with their interests and not necessarily those of the community.

Dependence on grants and donations inhibit the independence of grassroots organizations to select activities to undertake and to choose the most effective intervention strategies to achieve their goals. This is because the funders have their own predefined areas and types of activities that they are prepared to support, but which may not necessarily correspond with the needs of local actors and beneficiaries (Nyirabikali, 2016). The grassroots organizations peace and cohesion activities are also at a threat of programme discontinuity once donor-funds run out. Insufficiency of financial resources engenders a feeling of hopelessness among members of grassroots organizations and renders them impotent in successfully carrying out their activities and achieving their objectives (Batti, 2014). According Satterthwaite et al, (2011) and D'cruz and Mitlin(Undated) grassroots organizations in the informal settlements have joined together to form international network of national urban poor Federations in countries like Asia: Cambodia, India, Nepal, the Philippines, Sri Lanka; Africa: Kenya, Namibia, South Africa, Uganda and Zimbabwe. These groups of the urban poor use their savings as funding for their activities hence minimizing donor dependency.

Grassroots organizations especially those in the informal settlements highly depend on voluntariness of the members, which may be lacking. Grassroots organizations have diverse workforce of volunteers. According to Butcher (2017), volunteerism is a constraint to grassroots organizations because most volunteers are motivated by money rather than an altruistic sense to help. A research carried out by Karimanzira (2018) in Zimbabwe show that lack of commitment by the volunteers is because the local residents have no formal employment and they must balance the time they spend volunteering with the time they need to spend on domestic chores to fend for themselves and their families. The question of maintaining their motivation levels cannot be taken for granted particularly when the grassroots organizations offers no guarantee for financial. In addition, organization members dedicate much of their time to earning a living, so they have less time for voluntary grassroots organization activities. Most grassroots organizations may therefore focus on short term issues rather than long term issues like community peace and cohesion due to lack of dedicated participant.

Grassroots organizations face challenges in their formation stage. One of the major challenges is the opposition of local communities to new ideas of community cohesion, especially those that challenge traditional methods. A project research carried in India and Europe by Galvanek (2013) revealed that communities in certain cases do not accept certain aspects of a project initiative especially if the initiative is designed according to the foreign approach. Such opposition may be powerful and vocal enough to hinder, impede or ultimately derail a peace and cohesion initiative. The resistance can include non-participation, or cooperating with some aspects of an initiative, while subverting or ignoring others. The resistance can be due to Due to cultural differences in the community lack of understanding by the public or a blind faith on the part of the grassroots organization that they are doing what is best for the community. Bertotti et al (2016) also argue that public cynicism and distrust of the community peace and cohesion activities may also arise from a feeling that participation is not worth the effort or generally lack of time to participate in such activities due to the fact that residents in the informal settlement are poor and need to fend for sustenance. Grassroots organizations should provide flexible opportunities for participation in community peace and cohesion activities that are not dependent on time and place, can help increase participation levels.in addition, creating public awareness about the activities on community peace and cohesion can reduce levels of distrust.

Lack of collaboration and complementarity among grassroots organizations is a barrier to their effort to establish a peaceful and a cohesive community. A research carried out by Nyirabikali (2016) in Mali showed that most organizations engage in activities that are similar to those of their sister organizations. This results in competition where there should be complementarity and increased influence. Connolly and Powers (2018) also observed that there is inadequate coordination among grassroots organizations conducting activities in the same thematic areas and targeting related groups. 
A rich variety of grassroots organizations should be an asset in meeting citizens' needs and making societal development, but the lack of collaboration and complementarity limits their effectiveness. Negative competition for resources also undermines the reputation and the effectiveness of grassroots organization activities at community level. According to Radu and Radisc (2012) most grassroots organizations do not adopt an integrated approach and work separately, a fact that leads to ineffective utilization of existing resources, overlaps and/or gaps in providing services and lack common consensus on a shared agenda and steps to take to try and build a constituency of peace and cohesion. This leads to a great deal of suspicion, secrecy and lack of transparency among organizations. Many of these organizations large and small, intercede at community level without any community charting and implement developments without due regard to ongoing community initiatives. If members of the community are unable to work together, they face difficulties in participating in programs for community cohesion. A research carried by Barinaga (2018) revealed that Grassroots organizations in the informal settlements have formed Hybrid organizations to achieve social change. This involve building collaborations, and developing social networks to re-framing problems anew, as well as organizing spontaneous collective action for rapid responses.

Grassroots organizations have a deficiency in communication and consultation within and among themselves. A research carried out by Schuler (2008) showed that there is lack of communication infrastructure needed to support and sustain the social networks in grassroots organizations such as clubs, associations or groups. Most of the grassroots organizations aim at building an all-inclusive society but some grassroots organizations experience challenges in communicating with the public about their activities due to unclear mode of communication. They therefore face stigmatization because of lack of understanding by the public that hinder them from effectively organize, plan and enact their cohesion-oriented activities (Radu\&Radisc, 2012). Communication is also bared by class differences in the informal settlements. A research carried out by Madon and Sahay (2002) in Bangalore informal settlement in India showed that communities have variances terms of class caste, language and religion that create social barriers and the diversity not conducive communication and cohesion. According to Shailashree (2019) grassroots organizations can make the use of social media, advertisements, and website to encourage members of the public participate in community peace and cohesion initiatives.

Poverty, low state capacity and relatively low levels of aspiration among lower-income groups found in the urban informal settlements hinders grassroots organizations formed in such setting to embody their interests and help them address their multiple needs. A study carried out by Mitlin (2011) revealed that poverty and rising social disparities aggravate tensions and increase potential for the escalation of conflict, as people compete over resources and opportunities. A case study carried out in South Africa by Khambule and Siswana (2017) also revealed that inequality in economic opportunities leads to a reduction in interpersonal trust between groups that undermines grassroots organizations effort to promote community peace and cohesion.

\section{Methodology}

The descriptive research design was used to ground this study due to its ability to provide a picture of the phenomenon under study as it naturally happens. To execute the study, both quantitative and qualitative approaches were used for purposes of analytical triangulation.The target population comprised of household heads (44067), members of grassroots organizations engaging in peace and community cohesion (568), national government administrators (19), generating a total of 45260 . Using Cochran's formula: $\mathrm{n}=\frac{Z^{2} p q}{e^{2}}$, Where;

$\mathrm{n}$ is the sample size

$\mathrm{Z}$, which is equal to 1.96 , is the standard normal deviation at a confidence level of $95 \%$

e which is equal to 0.05 , is the desired level of precision (i.e. the margin of error),

$\mathrm{p}$ which is equal to 0.5 , is the (estimated) proportion of the population which has the attribute in question,

$\mathrm{q}$ is $1-\mathrm{p}$

a sample size of 384 was obtained. A mix of purposive, stratified, proportionate and simple random sampling procedures were used to distribute the sample size. Taking into account the various strata, 
relative population and the kind of information needed, data was distributed as follows: 338 members from among heads of households and members of the grassroots organizations were issued with questionnaires comprising of open and closed ended questions, 39 members drawn from the leadership of the 13 grassroots organizations participating in the study constituted three Focus Discussion Groups (FGDs) while the remaining 7 respondents comprising of government officials from various departments involved in peace and cohesion were interviewed. The resulting quantitative and qualitative data was analysed using a mix of descriptive statistics and content analysis respectively.

\section{Results}

\subsection{Challenges Facing Grassroots Organizations in Driving Community Peace and Cohesion}

To address this question, a Likert scale comprising of ten statements each with an array of five responses for respondents to choose from was developed. Among the research items guiding this particular investigation was negative ethnicity, inadequate government support, volatile political environment, failure to address historical injustices, lack of political goodwill and corruption.Figure 1 is a summary of findings on negative ethnicity
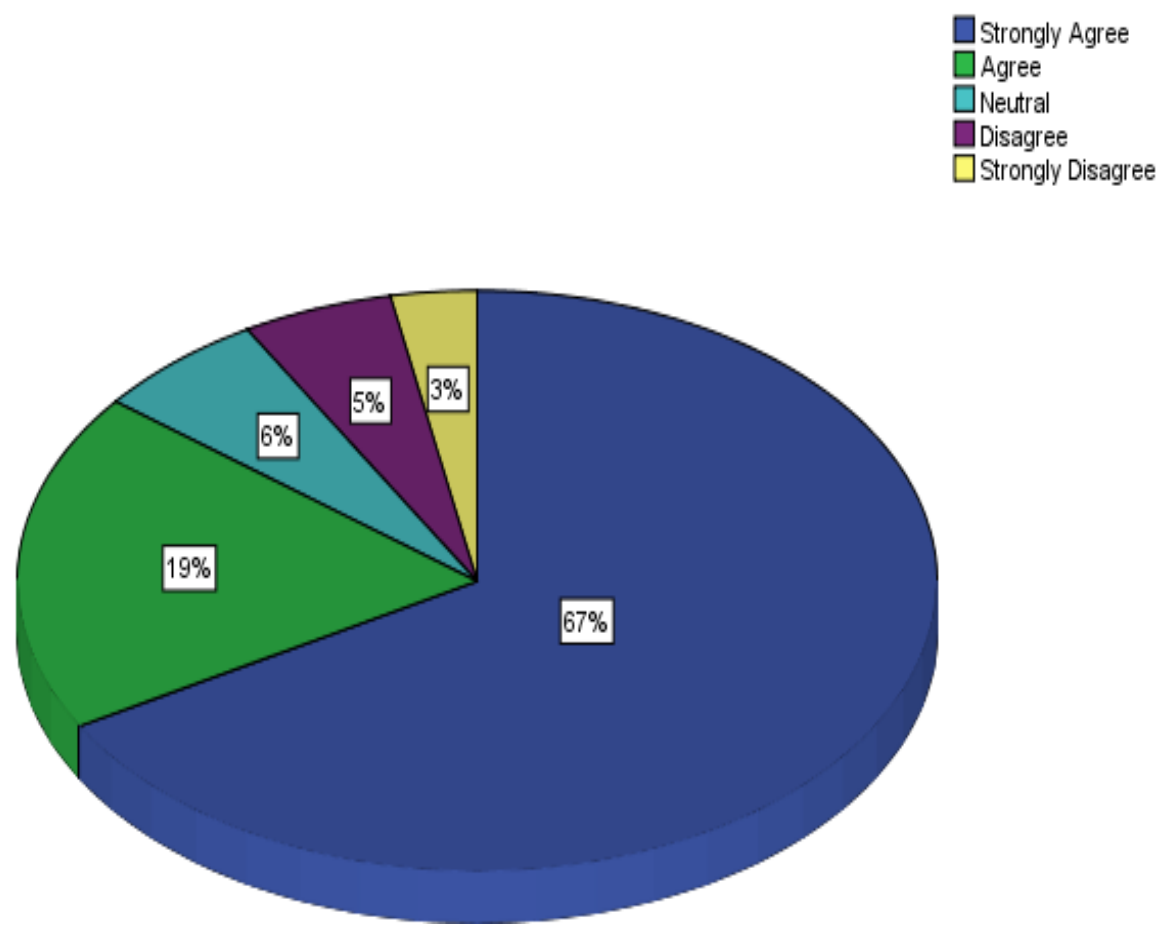

Figure1. Negative Ethnicity as a Barrier to Inter-communal cohesion

Figure 1 indicates that $67 \%$ of the respondents strongly agreed that negative ethnicity was undermining efforts made to enhance cohesion among the different ethnic communities living in Kibra informal settlement. About $19 \%$ of the participants agreed with this question statement while $6 \%$ expressed neutrality. A total of $8 \%$ of the respondents held a contrary view with $5 \%$ of them disagreeing that negative ethnicity was a barrier to fostering inter-communal cohesion in Kibra and the rest strongly disagreeing with the question statement. Jointly, a significant majority of the respondents, more than $85 \%$, were of the opinion that negative ethnicity was barrier to realization of a more cohesive ethnically diverse community in Kibra informal settlement. This can be explained by the fact that the informal settlement is made of diverse ethnic communities drawn from all regions in Kenya. Further division is brought about by the settlement patterns of these ethnic communities within the sprawling Kibra informal settlement. The different ethnic communities live in small niches defined by their ethnic backgrounds. This has the effect of explicitly segregating the ethnic groups along geographical boundaries hence entrenching the 'us' and 'them' narratives and stances. Since this has been allowed to happen both deliberately and subconsciously, the ethnic tribes easily get more divided unless steps and measures of cohesion, such as the ones being championed by the grassroots organizations, are put in place to bring back together the already divided ethnic groups in this and other informal settlements. 
The subject of negative ethnicity has been explored by many scholars as the principal driver of violent conflicts in Kenya and more so in the informal settings (CIPEV, 2008). The feelings of superiority emanating from ethnic antipathy are rampant among Kenyan communities and informal settings are a melting pot of such diversity and hence the likelihood of violence.

Another aspect that was investigated as a potential barrier of GROs effort in cohesion was lack of government support. Respondents were also asked to indicate their views on whether inadequacy of government support was an impediment to inter-communal cohesion among the different ethnic communities inhabiting Kibra informal settlement. The response was as shown in Figure 2.
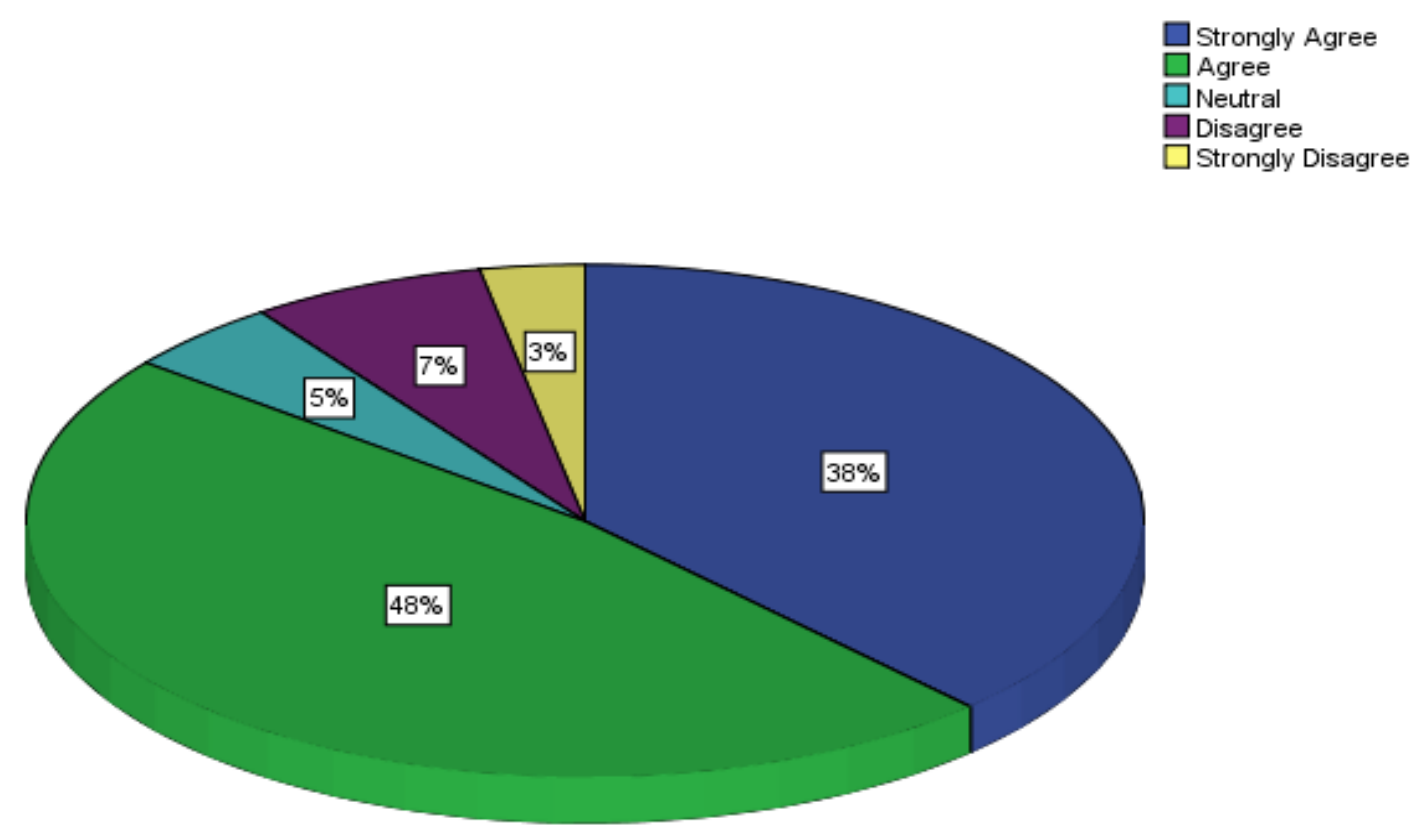

Figure2. Inadequate Government Support as an Impediment to Inter-communal Cohesion

From Figure 2, 38\% of the respondents strongly agreed that inadequate government support impeded inter-communal peace and cohesion in the informal settlement. About $48 \%$ of the survey participants agreed that inter-communal cohesion among residents of Kibra informal settlement was impeded by insufficient government support. Those who expressed impartiality with regard to this question were $5 \%$ of the respondents. Approximately $7 \%$ of the respondents agreed that inadequate support received from the government towards fostering inter-communal cohesion was an impediment to efforts made by grassroots organizations. Only $3 \%$ of the survey participants strongly disagreed with this question statement.

What comes out clearly from the results of this analysis is that for various reasons, the efforts of the grassroots organizations alone have not been adequate in stemming the problem of segregation and disintegration among the various ethnic groups living in Kibra informal settlement. The noticeable inadequate government support is a challenge to fostering inter-communal cohesion in Kibra informal settlement in a number of ways. First, failure by the government, either national or county or both to provide adequate material, financial and human resource support implies that the little resources the grassroots organizations have become very stretched and thinly spread hence reducing to some extent, the effectiveness of these organizations. Secondly, governments at both levels, through their agents, are usually at the fore front to champion inter-communal cohesion calls. Failure to actualize their talks by providing inadequate resources goes to indicate to various stakeholders that the government is only providing lip service but in real sense not serious in its calls for more cohesive and more united ethnically diverse communities. This has the effect of rolling back some of the gains made along the way since residents of the informal settlement may not take government representative seriously whenever they come to represent the government in various functions.

The third item examined the place of political volatility as an impediment to nurturing peace and cohesion in informal settlements by grassroots organizations. The findings were as illustrated in Figure 3. 


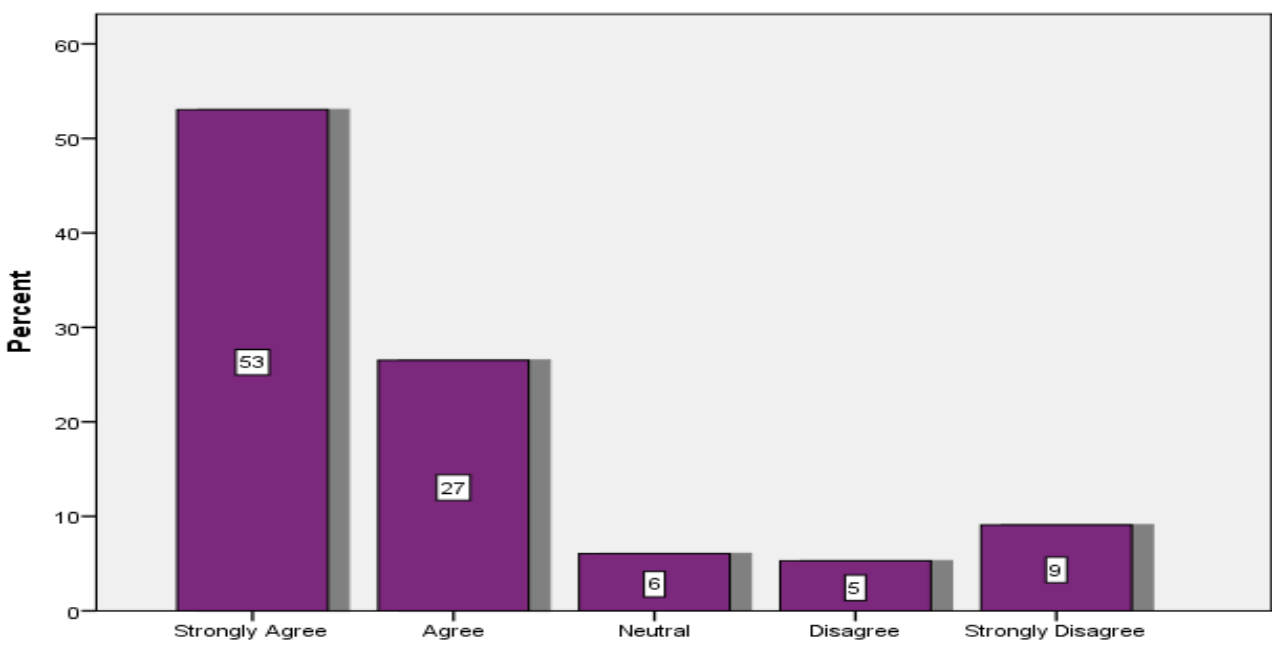

Figure3. Volatile Political Environment as an Obstacle to Fostering Inter-Communal Cohesion

Volatility of the political environment was reported to be an obstacle to enhancement of intercommunal cohesion in Kibra informal settlement. A cumulative proportion of $80 \%$ of the survey participants responded affirmatively to this question with 53\% of them strongly agreeing that volatile political environment derailed inter-communal cohesion efforts made by grassroots organizations in Kibra. The other $27 \%$ of the positive responders agreed with the question statement. About $5 \%$ of the respondents disagreed with the question statement on volatility of the political environment as a hindrance to cohesion among the different ethnic communities living in Kibra while $9 \%$ of the respondents strongly disagreed with the question statement. The rest $6 \%$ of the participants were neutral as captured in Figure 3.

The findings of the study, indicate that the volatile political environments significantly undermined efforts made by grassroots organizations to enhance community peace and cohesion in Kibra informal settlement. Explosive political atmosphere, mostly witnessed during electioneering periods, eroded the consolidated gains in terms of ethnic cohesion and roll back advances that have been made by grassroots organizations and the respective communities in enhancing inter-communal cohesion. The practice in Kibra informal settlement, as it is the case in most parts of Kenya, is that political alliances are formulated along ethnic lines. In addition to other desired and undesired outcomes, ethno-political movements and alliances served to divide individuals along ethnic lines especially during elections. Cohesive inter-communal structures that had been built prior to elections are brought down effortlessly and this subsequently sets back the peace and cohesion efforts by grassroots organizations.

The study went further to examine the place of cultural diversity and sensitivity in building intercommunal peace and cohesion. The findings were as presented in Figure 4.

$\square$ Strongly Agree
$\square$ Agree
$\square$ Neutral
$\square$ Disagree
$\square$ Strongly Disagree

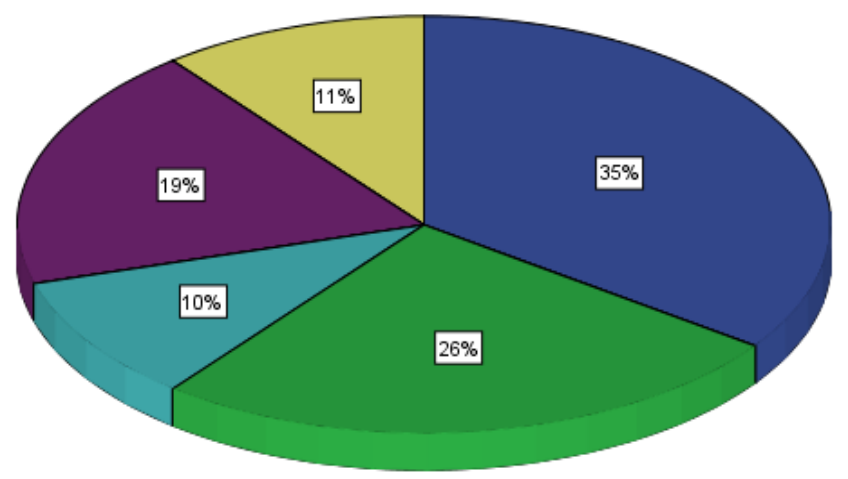

Figure4. Insensitivity to Cultural Diversity 
Figure 4 clearly indicate that insensitivity to cultural diversity was strongly agreed on by $35 \%$ of the respondents as a hurdle to enrichment of community peace and cohesion among the various ethnic communities in Kibra. Slightly more than one quarter of the respondents, 26\%, agreed that this element was a hindrance to efforts made by grassroots organizations towards peace and cohesion. Those who disagreed that insensitivity to cultural diversity impeded inter-communal cohesion in Kibra were $19 \%$ of the survey participants while $11 \%$ strongly disagreed with the question statement. The remaining $10 \%$ of the participants were neutral with regard to this question.

Acknowledging and appreciating the fact the cultures are diverse and different is an important step in embracing people from other cultural backgrounds and living harmoniously with them. Failure to observe these implies that cultural diversity and differences will be a source of disintegration instead of cohesion. This is what can be reliably made of the results presented in Figure 6. Insensitivity to cultural diversity potentially creates room for negative cultural stereotypes and other negative expressions towards people of different ethnic backgrounds. Such expressions and connotations widens rifts between people living in ethnically diverse communities like Kibra informal settlements thereby posing great challenges towards efforts made by grassroots organizations aimed at narrowing ethnic gaps and promoting cohesion in such communities.

The subject of historical injustices was explored to establish whether it was a barrier to cohesion in Kibra informal settlement and the findings were as per Figure 5.

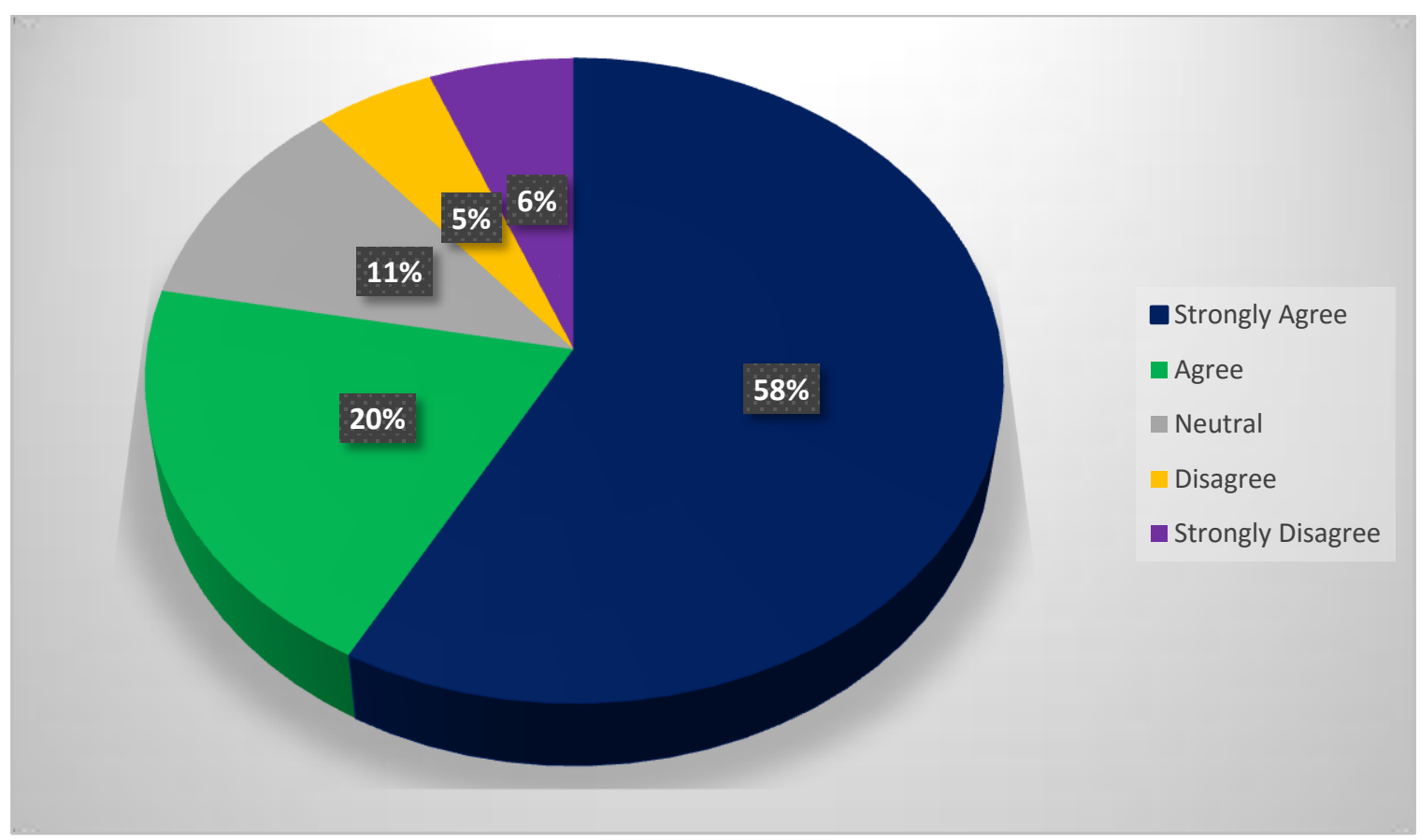

Figure5. Failure to Address Historical Injustices

From these results, $58 \%$ of the people who participated in the survey strongly agreed that this factor was a hindrance towards efforts made by grassroots organizations in Kibra to foster cohesion in the informal settlement. Nearly $20 \%$ of the respondents agreed that fostered intercommunity cohesion in Kibra was hindered by government's failure to address historical injustices that affected some of the residents of the informal settlement. Of those who held contrary views, 5\% disagreed with the question statement while $6 \%$ strongly disagreed that failure by the government to address historical injustices that affected a section of the residents of Kibra informal settlement was and impediment to realization of enhanced inter-communal cohesion in the community. The rest $11 \%$ of the respondents were nonaligned.

During the key informant interviews, one of the participants explained as follows:

The reality is different from what we speak because there is still deep-seated fear because of historical injustices. The Nubians feel that Kibra belongs to them and that and some people have forcefully settled on their land. This is like a time bomb, waiting to explode. (KII 7, 21/9/2020) 
Narratives of historical and grievances continue to stand in the way of inter-group reconciliation necessary for cohesion. Unaddressed historical injustices, especially in the form of land allocation by past political leaders and direct use of state power for violence against ethnic groups were deemed to propagate and foster inter-group grievances. From time to time, some of the ethnic groups residing in Kibra informal settlement have aired their grievances regarding historical injustices that were committed against their earlier generations that, to in their view, the government of Kenya has failed to handle. For instance, the Nubian community, who consider the entire area covered by Kibra informal settlement as their native land, have always complained that their land has increasingly been taken away from them not just by various government regimes but also by other communities who, over time, have acquired land in that area and made it their home. Apart from this land issue by the Nubian community, other ethnic tribes in Kibra site various injustices such as social injustices committed against them either by the various government regimes or by other ethnic tribes living in the area. The consequence of these concerns, whether valid or not, is that ethnic communities are pitted against one another whenever conflicts arise. This also potentially explain the geographically segregated ethnic sub-communities within the expansive community of Kibra informal settlement. As shown by the findings of the study, failure to address these injustices, real or imagined, undermine efforts of grassroots organizations to continuously build and maintain a cohesive community in the ethnically diverse Kibra informal settlement.

The researcher also wanted to find out if corruption was a barrier to grassroots organizations effort at community peace and cohesion building. $30 \%$ of the survey participants strongly agreed that corruption among some actors was an obstacle towards realization of the intended objectives of community peace and cohesion. An equivalent proportion (30\%) of the respondents agreed with the question statement. About 17\% of the respondents were indifferent while $13 \%$ of the participants disagreed that corruption among some stakeholders was impeding intercommunity cohesion in Kibra. The rest $11 \%$ of the respondents strongly disagreed that corruption activities among some actors was hindering efforts made by grassroots organizations to enhance inter-communal cohesion in the informal settlement as presented in Figure 6. This finding exposes and explains corruption as a structural and institutional barrier that significantly undermines efforts of grassroots organizations to attain community peace-and cohesion in Kibra informal settlement. Misappropriation, mismanagement and embezzlement of funds entrusted to the grassroots organizations and intended for various activities was reported by the respondents as one way that showed corruption.
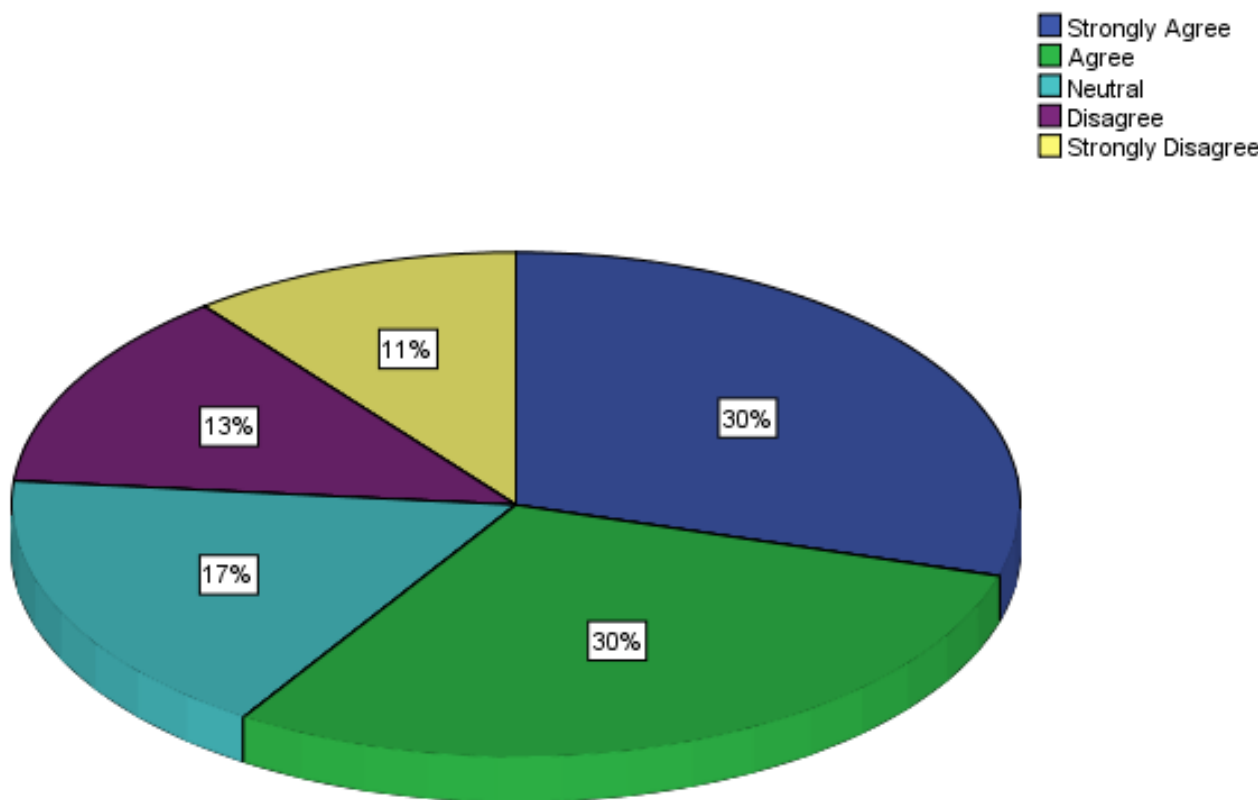

Figure6. Corruption Among Some Actors

During the FGDs one of the participants commented as follows:

In some instance, the officers of the grassroots organizations use resources entrusted to them to benefit their own small communities or for their personal use in the pretext they are implementing their organizations' activities. (Olympic FGD 1, 11/9/2020) 
Corruption-related structural barriers to equitable, accountable and transparent governance of the grassroots organizations also prevent the grassroots organizations from being effective in their activities. Existence of corruption in these and other forms thus become a significant barrier to the effective absorption of funds and resources intended for the noble courses of enhancing community peace and cohesion in Kibra. Entrenched corruption among other various stakeholders also provokes much anger thus increasing fragmentation community cohesion.

Another item of interest to the researcher was participation by the communities in peace and community cohesion activities as depicted in Figure 7.Approximately $25 \%$ of the respondents strongly agreed that poor communal participation arising from competing interests with economic activities impeded determinations made by grassroots organizations to foster inter-communal cohesion in Kibra. Another $42 \%$ of the participants responded positively to this question by agreeing that competing interest and activities such as economic activities derailed grassroots organizations' efforts to foster cohesion among the different ethnic communities residing in the informal settlement. About $8 \%$ of the respondents agreed with the question statement, $14 \%$ disagreed with it and $11 \%$ strongly disagreed with it.

It is evident that participation in grassroots organizations' activities aimed at entrenching community cohesion is affected by the need for residents of the informal settlement to go out and participate in income generating activities. This can be attributed to the fact that these are people who struggle to make ends meet and failure to go out to engage in gainful employment implies that they will not get their basic necessities. Consequently, they are highly likely to be torn between voluntarily participating in the grassroots organizations' activities, which in most instances they do not get any incomes, and going out to engage in income generating activities. More often, they will choose the latter over the former hence poor communal participation in this equally important initiative.

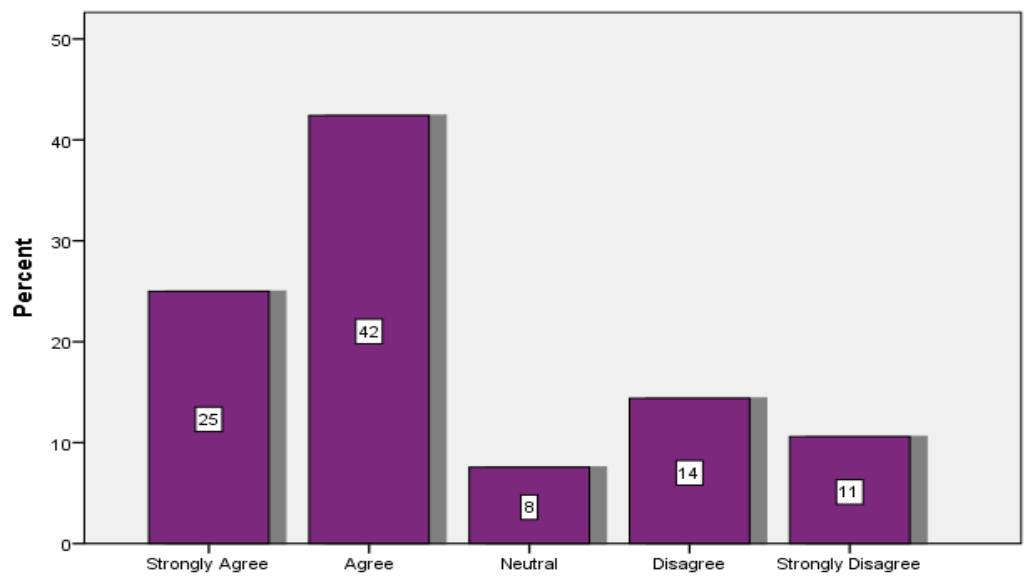

Figure7. Poor Communal Participation Arising from Competing Interests

The place of financial reward expectations was also explored to ascertain whether it was a hindrance in any way to GROs engagement with peace and cohesion as shown in Figure 8.

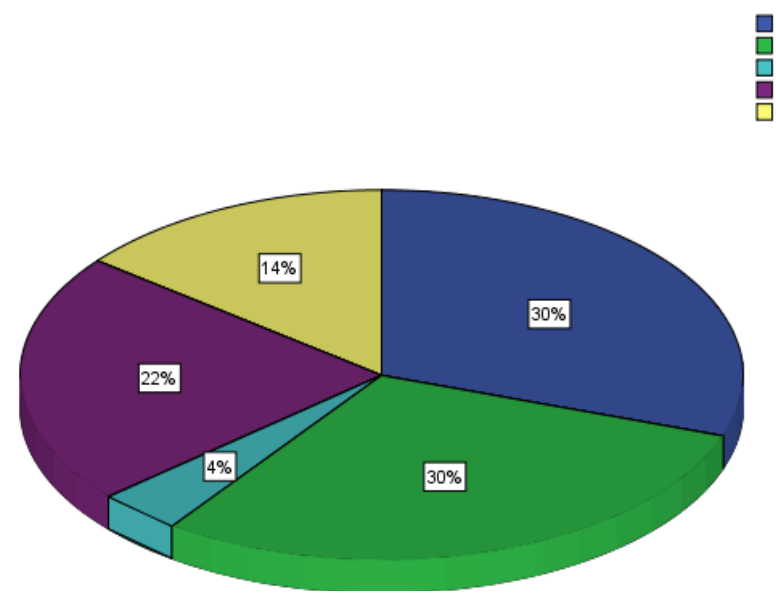

Figure8. Financial Incentives Expectations 
From the analysis of the collected data, it was established that $30 \%$ of the respondents strongly agreed that financial reward expectations derailed efforts made by grassroots organizations towards enhancing inter-communal cohesion in Kibra informal settlement. An equal proportion of the respondents agreed with the question on financial reward expectations as a hindrance to enhancement of inter-communal cohesion in Kibra. About 22\% of the respondents disagreed with the question statement while $14 \%$ of them strongly disagreed that expectations by participants in different activities organized by grassroots organizations aimed at enhancing inter-communal cohesion in Kibra impeded realization of the objective. Only $4 \%$ of the respondents were neutral as indicated in Figure 8.

This finding is, by extension, related to the immediate previous finding on competing interests. The almost unwritten rule in informal settlements like Kibra is that participation in any community activity must be accompanied by financial or other material compensations, but mostly financial incentives from the grassroots organizations. The 'justification' for this expectation given by the participants, especially adults and the youth, is that they would have been engaging in more meaningful income generating activities. The reason therefore this has been identified as a challenge by majority of the respondents is that failure to incentives the participants financially will negatively affect participation rates of the residents of the informal settlement. This therefore poses a great challenge to the grassroots organizations.

Resource allocation also formed a key part of the investigation into the barriers of peace and cohesion as undertaken by GROs and the results of this question are depicted in Figure 9.
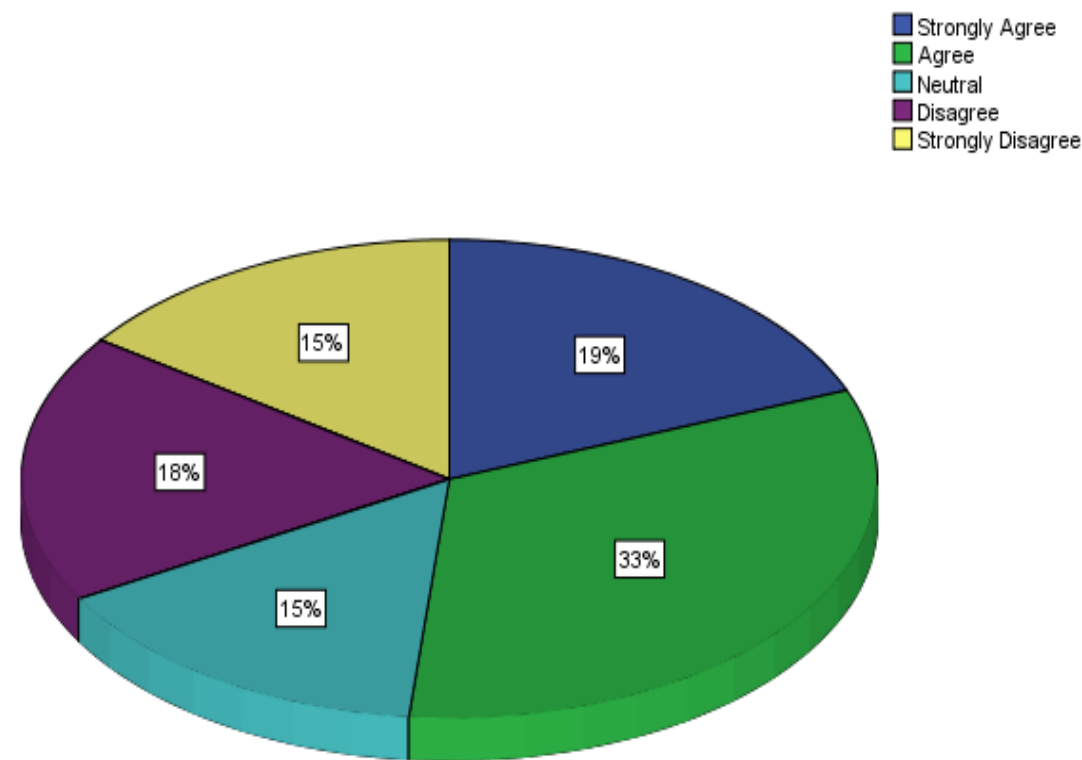

Figure9. Poor Allocation of Resources Due to Poor Prioritization

The study findings indicated that nearly one third of the respondents, $33 \%$, agreed that poor allocation of resource meant for enhancing inter-communal cohesion due to poor prioritization was a challenge to fostering community cohesion. The proportion that strongly agreed with this question statement was $19 \%$ while $15 \%$ of the respondents were neutral. Approximately $18 \%$ of the respondents disagreed with the question statement and the rest $15 \%$ strongly disagreed with it as shown in Figure 9.

Prioritization sets the organizational agenda in respect of what really matters, which is reflected in how not just resources are allocated but also the order of projects and activities organizations intend to implement. Done well, good prioritization of an organization's activities, projects and resources is highly likely lead to successful projects. Otherwise poor prioritization leads to project failure. Because the grassroots organizations are involved in carrying out numerous projects and activities within a calendar year, they need to be highly organized failure to which the activities will either not take off or even achieve the intended goals and objectives. It is however emerging from the finds of the study that effective prioritization is one of the challenges the institutions have which in turn affects the outcomes of their activities. It can be said, for instance, the scheduling of sporting and arts activities during school days by some of the organizations reflects on poor prioritization because during such 
period most of the youth who are targeted by such events are not available. Further, as pointed out during the interviews, allocation of significant resources to less intensive projects and activities also leaves the major activities deprived of resources hence poor outcomes of such activities and projects.

Finally, the subject of leadership and political goodwill was explored to establish whether it had any bearing on the implementation of peace and cohesion programmes by GROs. The results on this question are shown in Figure 10.
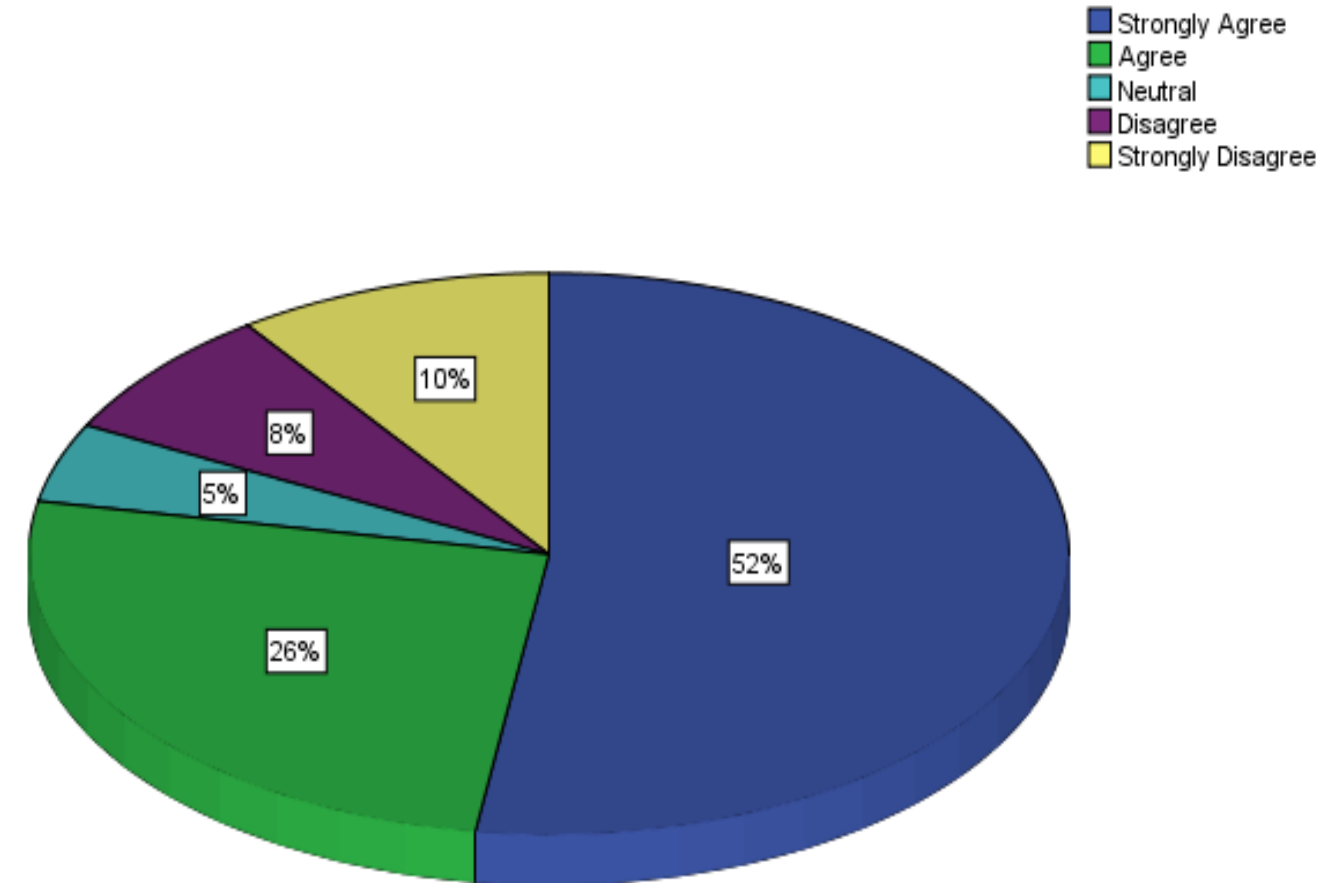

Figure4.15. Lack of Political Goodwill

The findings indicated that slightly more than half of the respondents, 52\%, strongly agreed that lack of political goodwill obstructed efforts made by grassroots organizations in Kibra towards fostering inter-communal cohesion among the various residents of the informal settlement. Just over one quarter of the respondents, $26 \%$, agreed with this question statement while $5 \%$ of them expressed indifference as shown in Figure 10. Out of the remaining 18\%, 8\% disagreed that fostering of intercommunal cohesion in Kibra was impeded by lack of political goodwill while the other $10 \%$ strongly disagreed with the question statement.

Voluntary decisions by political stakeholders to support activities of grassroots organizations in fostering inter-communal cohesion are quite essential in weaving an ethnically diverse cohesive community. The findings here imply that there are chances that politicians in Kibra informal settlement do not voluntarily come forward to support and uphold the activities of the grassroots organizations in promoting and fostering cohesion among the different ethnic communities living in Kibra. This finding is therefore consistent with the one on volatile political environment in the sense that is politicians come forward to promote cohesion among the different ethnic groups, then they would pit them against one another during political contests.

Donor conditionality was found to be a major challenge that the grassroots organizations faced in their operations. Some of the respondents indicated that the donors restricted the nature of activities that they would engage in in terms of community peace and campaigns. Other donors circumscribed the number of activities that a grassroots organization should carry out within a given time span. These restrictions reduced the effectiveness of the grassroots organizations because, as the respondents indicated, in order to achieve cohesion and peace in the informal settlement, sustenance of the activities was crucial.

Survey participants also expressed concern that mushrooming of many grassroots organizations that deal with community peace and cohesion undermined the essence of grassroots organisations that are active in enhancing community peace and cohesion in the informal settlement. Some of them have been found not to be genuine but have been established to be used as sources of income by their 
founders. This would in effect scare off genuine donors, well-wishers and NGOs and affect their funding and activities thereby rolling back the gains made in creating a community that is peaceful and cohesive.

Other respondents identified poverty as a barrier because it led to manipulation of the youths who disrupt peace in the community. The manipulation comes in the sense that people, especially men and youths are bought to demonstrate and disrupt peace and cohesion. Low education level among majority of the residents was also identified as a challenge. A key informant explained that:

Since most of them are not adequately formally educated, they cannot think for themselves or by the constitution. They always follow what the politicians say. They believe that what the politician that they believe in has said is right and final." (KII 4, 2/9/2020)

Failure by donors and well-wishers to avail activity fund in time was also found to be a major concern among majority of the respondents. Some of the survey participants indicated that when funds were not availed in time, the grassroots organizations were incapacitated because they were not in a position to carry out their planned activities. Compensating attendees of various events was also not possible and this meant that whenever the attendees were invited for meetings, majority of them would not show up until they were assured that their stipend was readily available.In other words, human capital and skills for community peace and cohesion can be undermined where donors' priorities shift too regularly. Moreover, suspicion and competition amongst donor organizations might be impeding information sharing that is critical for coordination and collaboration in peace-building efforts. This issue is compounded by the evolving nature of international funding. Donors and development partners are required to demonstrate measurable performance records for investment of their resources, but it remains very difficult to measure "social cohesion." Even though the concept is difficult to measure, however, does not mean is not a critical need for the realization of stable peace and human development. Consequently, the grassroots organizations would be at a loss and any progress they had previously made would be eroded gradually whenever they were inactive.

\subsection{Opportunities for Grassroots organizations to enhance their effectiveness in community peace and cohesion in Kibra informal settlement}

This aspect of the study question sought to establish the available opportunities that grassroots organizations could capitalize on to enhance their effectiveness in building community peace and cohesion. Among the opportunities reported by the study's respondents were partnerships with nongovernmental organizations, collaboration within and between the grassroots organizations, among others. These opportunities are discussed hereunder.

The study established that grassroots organizations and the local communities as well as the government agencies did not work together in planning the activities and programs. The effect of the lack of coordination and internal coherence led to duplication of programs and rejection of funding opportunities by potential donors citing repetition. It would thus be important for the grassroots organization to work together and with the government in planning and sharing of responsibilities to avoid duplication and undercutting each other in terms of funding.

The study also established that the grassroots organizations did not have their own sustainable streams of funding and were entirely dependent on funding. The respondents suggested that beginning or setting up income generating programs would not only empower the community by way of employment but also provide the organizations with the required funding to carry out their activities without having to rely on donors.

Moreover, the respondents suggested the establishment of a structured engagement between grassroots organizations and the community, to entrench community participation in their activities and programs. The study established that this suggestion was informed on the understanding that the community did not fully own the programs and hence treated them as income generating pathways were they only attend if they were paid to do so. As such, the community did not fully understand their role and input in the process.

The respondents acknowledged that grassroots organizations in Kibra Informal settlement worked in partnership with Non-Governmental Organizations (NGO) to promote and champion the peace and cohesion process in the study area. For example before the 2017 elections various NGO operating in 
the informal settlement such as Kibra which included Umande Trust, Octopizzo Foundation Shofco, Hodi Africa, Map Kibra trust among others organized formed a collaborative peace forum with Grassroots organizations to break down prejudices, encourage intercommunity dialogue create awareness about peaceful General Election. Organizations such as Carolina for Kibra have formed a sub group known as JamiiyaKibra composed of stake holders from various grassroots organizations working on peace and cohesion programs in Kibra to help in the coordination of peace activities and to avoid duplication.

The respondents also admitted that much of the peace and cohesion activities by the grassroots organizations were funded by NGO. The NGO like Carolina for Kibra, Shining Hope for Communities(SHOFCO), Umande trust were mentioned by the respondents as the NGOs providing support to grassroots organizations in form of funding, leadership training and also organize grassroots communities to pool resources and gain ownership for their activities. Umande trust offer services such as providing affordable toilets for Kibras residents and use such services as entry point for peace and cohesion dialogue.

Kenya Tuna Uwezo (We Have the Power) was also mentioned as one of the NGO that has played an instrumental role in reduce politically-motivated conflict, interethnic violence and sectarian violence in the informal settlements in Nairobi. Kenya Tuna Uwezo helped grassroots organizations to develop the technical and organizational capacity train leaders and organize various to work effectively with one another across ethnic lines to create community peace and cohesion in the informal settlement. Kenya Tuna Uwezo formed 'Cohesion champions' composed of volunteers from the grassroots organizations and the community to help spread the message on community peace and cohesion. The cohesion champions used the social media platforms such as WhatsApp and Facebook to help the youth to interact and dialogue with one another. This is an indication that there is a consultative effort by various stake holders enhance community peace and cohesion in Kibra informal settlement.

Thus, there existed various opportunities which if the grassroots organizations capitalized on could enhance their effectiveness in building sustainable community peace and cohesion.

\section{CONCLUSION}

This study argues that the challenges that grassroots organizations face are mostly structural and can largely be resolved if there is goodwill and collaboration from state actors. The goodwill being alluded to here should primarily come from local political stakeholders, government officials and civil society who are key pillars of development of community peace and cohesion particularly in post-conflict regeneration. The challenges they face are surmountable to the extent that there is that cooperation and unity of purpose as each stakeholder brings on board a different, yet important contribution to the entire peacebuilding and cohesion enterprise. The study roots for grassroots organizations actors'inclusion in all phases of peace and cohesion programming,ostensibly to help highlight possible pitfalls in the programming and collectively find ways of circumventing such eventualities. Their active engagement is important because it help to integrate perspectives of a broader society and also increase the chance of reaching a broader political and social consensus that is necessary to make peace processes and programs sustainable. Through the grassroots organizations, local capacity for peace and cohesion is made manifest, hence the need to support their activities and collaborate with them to tap into the various strengths they possess.

\section{REFERENCES}

[1] Aguilar-Francis, R. A. (2012). Promoting the right to life, liberty and security through grassroots youth empowerment: the case of the MajiMazuri organization in the Mathare informal settlements, Kenya following the 2007 post-election violence (Master's thesis, UniversitetetiTroms $\emptyset$ ).

[2] Allport, G. W. (1954). The Nature of Prejudice. Cambridge, Mass. Addison-Wesley Publication Company

[3] Batti, R.C. (2014) Challenges Facing Local NGOs in Resource Mobilization. Humanities and Social Sciences. Vol. 2, 3: 57-64.

[4] Bloomfield, J., \& Fisher, M. J. (2019). Quantitative research design. Journal of the Australasian Rehabilitation Nurses Association, 22(2), 27-30.

[5] Butcher, J. \& C. J. Einolf (Eds.). (2017). Perspectives on volunteering: Voices from the South. Springer: Cham, Switzerland

[6] Campos, M. J. Z., Barinaga, E., Kain, J. H., Oloko, M., \& Zapata, P. (2019). Organising Grassroots Initiatives for a More Inclusive Governance: Constructing the City from Below. 
[7] Connolly, L., \& Powers, L., (2018). Local Networks for Peace: Lessons from Community-Led Peacebuilding. New York: International Peace Institute. Retrieved April 2, 2018 from https://www.ipinst.org/2018/09/local-networks-for-peace-lessons-from-community-led-peacebuilding

[8] Cox, D. F., Orsborn, C. R. \& Sisk, T. D. (2014). Religion, Peace-building, and Social Cohesion in Conflict-affected Countries. Research Report University of Denver-Iliff and Josef Korbel School of International Studies.

[9] Cox, M. (Ed.). (2008). Social capital and peace-building: Creating and resolving conflict with trust and social networks. Routledge.

[10] Galvanek, J.B. (2013). Translating Peacebuilding Rationalities into Practice. Local Agency and Everyday Resistance,Berghof Foundation Operations GmbH

[11] Howell, J. \& Pearce, J., (2002). Civil Society and Development, A Critical Exploration, Lynne Rienner Publishers

[12] Karimanzira, E. (2018). Tutors' perceptions on how peace and reconciliation advances frontiers of knowledge in the field of development studies. International Open and Distance Learning Journal, 2(4).

[13] Khambule, I. \& Siswana, B. (2017). How Inequalities undermine Social Cohesion: A Case study of South Africa Human Science Research Council.

[14] Lett, H. A. (1945). Techniques for achieving interracial cooperation. Proceedings of the Institute on Race Relations and Community Organization. Chicago: University of Chicago and the American Council on Race Relations

[15] Madon, S. \& Sahay, S. (2002) An information-based model of NGO mediation for the empowerment of slum dwellers in Bangalore. Information Society, 18 (1). pp. 13-19

[16] Mitlin, D. (2011). Civil Society and Urban Poverty: Examining Complexity. Environment and Urbanization. 13(2), pp. 151-173.

[17] Mung'ou, C. (2018). The Role of Non-State Actors in Enhancing Peacebuilding Among Women in Mount Elgon Region, Kenya. Journal of African Conflicts and Peace Studies, 4(1), 1.

[18] Mwaniki, T. W. (2007). Peace Building \& Conflict Management in Kenya: Joint Case Study of Northrift Region of Kenya (Vol. 15). Paulines Publications Africa.

[19] Nyirabikali, G. (2008). 'Participatory Democracy, Pluralistic Governance, and Peace Education for Leaders: Lessons from the Kenyan Case'. Conflict Trends, Issue 2, pp. $34-40$

[20] Pagallo, E. (2017). Exploring women's inclusion and contribution to the building of infrastructures for peace from grassroots initiatives in Kenya (Doctoral dissertation, UniversitatJaume I).

[21] Radu, R., Radisic, J., Suciu, A., Tuna, A., Steiner, F. Fedorko, B. \&Cerry, V. (2012). Well-being Reconsidered: Empowering Grassroots Organizations. Experiences from the Grassroots Europe for Local Wellbeing Initiative.

[22] Ringera, K. (2014). The role of women in grassroots peacebuilding in Kenya. Building Peace from Within, 172-98.

[23] Satterthwaite, D., Mitlin, D., \& Patel, S. (2011). Engaging with the urban poor and their organizations for poverty reduction and urban governance. New York, US: UNDP.

[24] Schiefer, D., \& van der Noll, J., (2017). The Essentials of Social Cohesion: A Literature Review: Social Indicators Research. An International and Interdisciplinary Journal for Quality-of-Life Measurement, Springer, 132(2), pp. 579-603.

[25] Schmidt, N. A., \& Brown, J. M. (2012). Evidence-based Practice for Nurses: Appraisal and Application of Research. Sudbury, MA: Jones \& Bartlett Learning

[26] Svensson, P. G., \& Woods, H. (2017). A systematic overview of sport for development and peace organisations. Journal of Sport for Development, 5(9), 36-48.

[27] Williams, R. M., Jr. (1947). The reduction of intergroup tensions. New York: Social Science Research Council.

Citation: Christine JumaAgaya, Godfrey Ungaya, Emily Okuto. "Challenges and Opportunities for Grassroots Organizations-Led Peacebuilding and Cohesion in Kibra Informal Settlement, Kenya" International Journal of Humanities Social Sciences and Education (IJHSSE), vol 8, no. 4, 2021, pp. 256-270. doi: https://doi.org/10.20431/2349-0381.0804021.

Copyright: (C) 2021 Authors. This is an open-access article distributed under the terms of the Creative Commons Attribution License, which permits unrestricted use, distribution, and reproduction in any medium, provided the original author and source are credited. 